\title{
Vigilância epidemiológica da presença do vírus da raiva a partir do exame de imunofluorescência direta aplicada ao tecido cerebral de uma amostra da população canina do município de Mogi-Guaçu, SP, Brasil. Ensaio probabilístico a partir de série histórica de 1989 a 1999
}

Haroldo de Barros Ferreira PINTO';

Omar MIGUEL ${ }^{2}$;

Alair ASSIS ${ }^{3}$

Correspondência para: HAROLDO DE BARROS FERREIRA PINTO

Centro de Controle de Zoonoses da Prefeitura Municipal de São Paulo

Rua Santa Eulália, 86 - Santana

02031-020 - São Paulo - SP

haroldob@prefeitura.sp.gov.br

Recebido para publicação: 19/09/2003 Aprovado para publicação: 22/06/2004

1 - Centro de Controle de Zoonoses da Prefeitura Municipal de São Paulo, São Paulo - SP.

2 - Faculdade de Saúde Pública da USP, São Paulo - SP; Universidade de Santo Amaro, São Paulo - SP.

3 - Centro de Controle de Zoonoses da Prefeitura Municipal de Mogi-Guaçu, Mogi-Guaçu - SP; Universidade Paulista - UNIP, São Paulo - SP

\section{Resumo}

Foi analisada a validade do exame laboratorial sistemático do sistema nervoso de uma amostra da população canina de uma dada área, como estratégia destinada a vigilância epidemiológica da circulação do vírus da raiva. Foi empregado o banco de dados do município de Mogi-Guacú, SP, Brasil, referente a série histórica compreendida entre janeiro de 1989 a dezembro de 1999. Neste período foram examinados 1167 animais dos quais $130(11,2 \%)$ foram positivos ao teste de imunofluorescência aplicada a raiva. $\mathrm{O}$ tamanho da amostra para a detecção de pelo menos um animal positivo foi calculado pela fórmula $\mathrm{n}=\left\{1-(1-\alpha)^{1 / \mathrm{d}}\right\}(\mathrm{N}-\mathrm{d} / 2\}+1$. No período de 1989 a $1994 \mathrm{o}$ tamanho da amostra foi calculado a partir do número real de casos registrados. Nos anos de 1995 a 1999 como não houve novos casos de raiva canina, a análise considerou hipoteticamente a presença de um caso confirmado. Também foi efetuada a simulação do número de casos de raiva que deveriam ocorrer para que a amostra efetivamente utilizada pelo Serviço de controle da raiva fosse capaz de revelar a presença de pelo menos um animal positivo. Os resultados obtidos demonstraram que no período de 1989 a 1994 em que a freqüência anual de casos de raiva canina variou de 5 a 75 o tamanho das amostras ideal seria de 12.400 a 12.922; já no período de 1995 a 1999, em que não foram diagnosticados casos de raiva canina, se ocorresse pelo menos um registro, o tamanho da amostra seria de 13.257 a 14.698. Do exposto depreende-se que em termos probabilísticos, a estratégia proposta não é indicada para a vigilância epidemiológica da presença do vírus da raiva, quando em situação de controle, pois o número de animais a serem examinados é inviável para situações concretas.

\section{Introdução}

Reconhecida desde a antigüidade, a raiva é uma infecção aguda do sistema

\section{Palavras-chave:}

Cães.

Vigilância Epidemiológica. Raiva.

Mogi-Guaçu.

São Paulo (Estado). 
A transmissão da raiva, ocorre pela inoculação do vírus contido na saliva do animal infectado, pela mordedura e, mais raramente, pela arranhadura e lambedura de mucosas ${ }^{2}$.

Nos países em desenvolvimento, o cão sempre foi considerado a principal fonte de infecção da raiva em área urbana. Nas Américas, entre 1990 e 1997, o cão foi responsável por $79,9 \%$ do total de casos humanos. Porem, a elevada população de cães não é o único fator que contribui para a ocorrência de raiva, pois, nos países em desenvolvimento, a relação entre população humana e canina é semelhante àquela observada nos países industrializados ${ }^{3}$. Nos países desenvolvidos, foi encontrada uma relação de cães por habitante de 1:10 e 1:8 Nos países em desenvolvimento, a relação de 1:8 foi encontrada em 14 países dos continentes africano, asiático, sul-americano e centro-americano ${ }^{4}$.

O Brasil, desde a implantação do programa de controle da raiva em áreas urbanas de acordo com as normas da OMS/OPS, vem apresentando um declínio de casos de raiva em cães, e em seres humanos ${ }^{5}$. Foram registrados, entre os anos de 1989 e 1999, 468 casos de raiva humana, correspondendo a $24 \%$ do total de casos da América Latina no mesmo período. De 1990 a 1999, em 75\% (267) do casos notificados, o cão foi o animal transmissor ${ }^{4}$.

Em Mogi-Guaçu SP, até meados de 1989, a única atividade voltada para o controle da raiva era a campanha anual de vacinação dos animais domésticos. O exame de cérebros de cães pelo teste de imunofluorescência direta aplicada a raiva era efetuado de forma descontinuada e sem planejamento. A partir de julho de 1989, com a criação do Centro de Controle de Zoonoses (CCZ), foram aprimoradas as ações para o controle da raiva no Município de Mogi-Guaçu ${ }^{6}$. A partir de então, o diagnóstico laboratorial, passou a ser o instrumento fundamental para a confirmação da presença do vírus na população canina e o desencadeamento de medidas de controle de foco destinadas ao bloqueio da circulação do vírus rábico nas espécies animais envolvidas, bem como para a orientação do tratamento anti-rábico em seres humanos expostos ao risco da infecção ${ }^{2}$.

O município de Mogi-Guaçu passou a proceder o exame de imunofluorescência direta aplicada a raiva em uma amostra da população canina local para identificar a circulação do vírus. O tamanho da amostra enviada para laboratório foi de aproximadamente $0,2 \%$ da população canina estimada. Este parâmetro foi estabelecido por $\mathrm{Schneider}^{7}$, através das informações obtidas junto aos coordenadores estaduais do Programa de Controle da Raiva e da análise das informações contidas nas fichas de investigação, no período de 1980 e 1986. Essas avaliações mostraram que, naquelas cidades onde a vigilância epidemiológica era considerada boa e a raiva havia sido controlada, o percentual de amostras enviadas para diagnóstico era em torno de $0,2 \%$. O objetivo do presente trabalho é o de aplicar o cálculo de probabilidades para a avaliação do poder desta estratégia para revelar a presença do vírus na respectiva população.

\section{Materiais e Métodos}

No período de 1989 e 1999, a população humana residente na cidade de Mogi-Guaçu, foi em média de 110.000 habitantes e a população canina estimada de 13.750 animais, relação de um animal para cada oito habitantes ${ }^{8}$.

A colheita das amostras de sistema nervoso foi efetuada por técnicos no CCZ de Mogi-Guaçu em animais que apresentavam quadro neurológico sugestivo de raiva, animais agressores ou apreendidos em áreas de foco e não resgatados pelos proprietários e em cães atropelados nas vias públicas. Após a colheita, as amostras eram remetidas em refrigeração para o laboratório do CCZ de São Paulo. Foi enviado 0,2\% de amostras, de acordo com o preconizado pelo Programa Nacional de Controle da 
Raiva, conforme os estudos de Schneider?

Segundo Thrusfield ${ }^{9}$, o cálculo do tamanho de amostras para a detecção de pelo menos um animal infectado na população estimada poderia ser efetuado com o emprego da fórmula: $n=\left\{1-(1-\alpha)^{1 / d}\right\}$ $(\mathrm{N}-\mathrm{d} / 2\}+1$, onde $\mathrm{N}$ é o tamanho da população em estudo, n é o tamanho da amostra necessária, $1-\alpha$ representa a probabilidade de encontrar pelo menos um animal doente na amostra (o nível de confiança adotado foi de 0,05$)$, e d é o número de animais doentes na população.

Os exames de imunofluorescência direta aplicada a raiva (RIFD) foram executados como preconizado por Goldwasser e Kissiling ${ }^{10}$, no laboratório do CCZ de São Paulo, que é um dos laboratórios de referência do Estado. Os materiais também foram submetidos a prova de inoculação intracerebral em camundongos ${ }^{11}$.

\section{Resultados}

Os resultados são apresentados nas tabelas de 1 a 4 e nas figuras 1 e 2 .

A tabela 1 apresenta em números absolutos, o número de amostras de cérebros de cães enviadas para o diagnóstico de raiva, distribuídos mês a mês, no período compreendido entre janeiro de 1989 a dezembro de 1999. Os resultados dos exames laboratoriais enviados para o diagnóstico de raiva, mês a mês, são apresentados na tabela 2 , expressos em porcentagem.

A tabela 3, mostra os valores do coeficiente de incidência dos casos de raiva entre 1989 e 1999.

A tabela 4 apresenta o número de animais a serem examinados para detectar pelo menos um animal positivo para a raiva, com $95 \%$ de confiança, a partir da população canina estimada, ano a ano, no Município de Mogi-Guaçu, no período estudado.

O coeficiente de incidência dos casos de raiva por ano está representado na figura 1 e a porcentagem mensal, está representada na figura 2 , no período compreendido entre 1989 a 1999.

\section{Discussão}

No período compreendido entre o mês de janeiro de 1989 a dezembro de 1999, foram enviados para diagnóstico laboratorial, pelo CCZ da cidade de Mogi-

Tabela 1 - Amostras de cérebro de cães enviadas para diagnóstico de raiva, segundo resultado laboratorial mês a mês, município de Mogi-Guaçu, Estado de São Paulo, de janeiro de 1989 a dezembro de 1999

\begin{tabular}{|c|c|c|c|c|c|c|c|c|c|c|c|c|c|c|c|c|c|c|c|c|c|c|c|c|c|}
\hline \multirow{2}{*}{$\begin{array}{c}\text { Mês } \\
\text { Res. } \\
\text { Ano }\end{array}$} & \multicolumn{2}{|c|}{ Jan } & \multicolumn{2}{|c|}{ Fev } & \multicolumn{2}{|c|}{ Mar } & \multicolumn{2}{|c|}{ Abr } & \multicolumn{2}{|c|}{ Maio } & \multicolumn{2}{|c|}{ Jun } & \multicolumn{2}{|c|}{ Jul } & \multicolumn{2}{|c|}{ Ago } & \multicolumn{2}{|c|}{ Set } & \multicolumn{2}{|c|}{ Out } & \multicolumn{2}{|c|}{ Nov } & \multicolumn{2}{|c|}{ Dez } & \multirow[t]{2}{*}{ Total } \\
\hline & pos & r & . & ne & 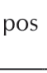 & & & 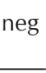 & 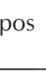 & & 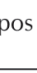 & & 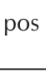 & neg & nes & . & & 5 & (5) & & & & & & \\
\hline 1989 & 0 & 0 & 0 & 0 & 0 & 0 & 0 & 0 & 0 & 0 & 0 & 0 & 1 & 3 & 4 & 3 & 5 & 2 & 7 & 2 & 0 & . & 2 & 0 & 29 \\
\hline 1990 & 5 & 16 & 2 & 5 & 13 & 2 & 2 & 6 & 1 & 1 & 6 & 27 & 12 & 10 & 10 & 12 & 11 & 10 & 8 & 25 & 3 & 15 & 2 & 14 & 218 \\
\hline 1991 & 0 & 8 & 0 & 2 & 2 & 14 & 1 & 13 & 0 & 7 & 1 & 11 & 2 & 8 & 0 & 8 & 0 & 10 & 0 & 5 & 0 & 11 & 0 & 16 & 119 \\
\hline 1992 & 0 & 12 & 0 & 0 & 0 & 3 & 1 & 8 & 0 & 11 & 1 & 9 & 0 & 21 & 3 & 13 & 4 & 22 & 0 & 7 & 0 & 14 & 0 & 6 & 135 \\
\hline 1993 & 2 & 4 & 0 & 9 & 0 & 4 & 0 & 12 & 0 & 10 & 0 & 3 & 2 & 12 & 3 & 12 & 2 & 10 & 4 & 5 & 1 & ? & 2 & 7 & 106 \\
\hline 1994 & 3 & 9 & 0 & 7 & 0 & 7 & 1 & 3 & 1 & 5 & 0 & 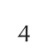 & 0 & 4 & 0 & 6 & 0 & 13 & 0 & 5 & 0 & 1 & 0 & 4 & 73 \\
\hline 1995 & 0 & 4 & 0 & 4 & 0 & 12 & 0 & 4 & 0 & 8 & 0 & 7 & 0 & 10 & 0 & 13 & 0 & 12 & 0 & 13 & 0 & 9 & 0 & 7 & 103 \\
\hline 1996 & 0 & 1 & 0 & 4 & 0 & 18 & 0 & 11 & 0 & 7 & 0 & 9 & 0 & 0 & 0 & 6 & 0 & 9 & 0 & 12 & 0 & 3 & 0 & 1 & 81 \\
\hline 1997 & 0 & 4 & 0 & 3 & 0 & 5 & 0 & 1 & 0 & 1 & 0 & $J$ & 0 & 10 & 0 & 3 & 0 & 11 & 0 & 8 & 0 & 3 & 0 & 4 & 58 \\
\hline 1998 & 0 & 6 & 0 & 2 & 0 & 4 & 0 & 2 & 0 & 5 & 0 & 6 & 0 & 7 & 0 & 11 & 0 & 11 & 0 & 4 & 0 & 4 & 0 & 7 & 69 \\
\hline 1999 & 0 & 8 & 0 & 22 & 0 & 1 & 0 & 4 & 0 & 5 & 0 & 7 & 0 & 17 & 0 & 14 & 0 & 11 & 0 & 30 & 0 & 32 & 0 & 25 & 176 \\
\hline Total & 10 & 72 & 2 & 58 & 15 & 70 & 5 & 64 & 2 & 60 & 8 & 88 & 17 & 102 & 20 & 101 & 22 & 121 & 19 & 116 & 4 & 94 & 6 & 91 & 1167 \\
\hline
\end{tabular}

Fonte: Centro de Controle de Zoonoses. Prefeitura do Município de São Paulo 
Tabela 2 - Amostras de cérebro de cães enviadas para diagnóstico laboratorial, segundo o mês, ano a ano, município de Mogi-Guaçu, Estado de São Paulo, de janeiro de 1989 a dezembro de 1999

\begin{tabular}{c|cccccccccccc|c}
\hline $\begin{array}{c}\text { Mês } \\
\text { Ano }\end{array}$ & Jan & Fev & Mar & Abr & Maio & Jun & Jul & Ago & Set & Out & Nov & Dez & Total \\
\hline 1989 & 0 & 0 & 0 & 0 & 0 & 0 & 3 & 3 & 2 & 2 & 0 & 0 & 10 \\
1990 & 16 & 5 & 2 & 6 & 1 & 27 & 10 & 12 & 10 & 25 & 15 & 14 & 143 \\
1991 & 8 & 2 & 14 & 13 & 7 & 11 & 8 & 8 & 10 & 5 & 11 & 16 & 113 \\
1992 & 12 & 0 & 3 & 8 & 11 & 9 & 21 & 13 & 22 & 7 & 14 & 6 & 126 \\
1993 & 4 & 9 & 4 & 12 & 10 & 3 & 12 & 12 & 10 & 5 & 2 & 7 & 90 \\
1994 & 9 & 7 & 7 & 3 & 5 & 4 & 4 & 6 & 13 & 5 & 1 & 4 & 68 \\
1995 & 4 & 4 & 12 & 4 & 8 & 7 & 10 & 13 & 12 & 13 & 9 & 7 & 103 \\
1996 & 1 & 4 & 18 & 11 & 7 & 9 & 0 & 6 & 9 & 12 & 3 & 1 & 81 \\
1997 & 4 & 3 & 5 & 1 & 1 & 5 & 10 & 3 & 11 & 8 & 3 & 4 & 58 \\
1998 & 6 & 2 & 4 & 2 & 5 & 6 & 7 & 11 & 11 & 4 & 4 & 7 & 69 \\
1999 & 8 & 22 & 1 & 4 & 5 & 7 & 17 & 11 & 11 & 30 & 32 & 25 & 176 \\
\hline Total & 72 & 58 & 70 & 64 & 60 & 88 & 102 & 121 & 121 & 116 & 94 & 91 & 1037 \\
\hline
\end{tabular}

Fonte: Centro de Controle de Zoonoses. Prefeitura do Município de São Paulo

Tabela 3 - Distribuição dos coeficientes de incidência e das amostras positivas de raiva de raiva canina, segundo o ano e o tamanho da população canina estimada, Município de Mogi-Guaçu, Estado de São Paulo, Brasil, de janeiro de 1989 a dezembro de 1999

\begin{tabular}{cccccc}
\hline Ano & $\begin{array}{c}\text { População } \\
\text { canina estimada }\end{array}$ & $0,2 \%$ & $\begin{array}{c}\text { Amostras } \\
\text { enviadas }\end{array}$ & $\begin{array}{c}\text { Amostras } \\
\text { positivas }\end{array}$ & $\begin{array}{c}\text { Coeficiente de } \\
\text { incidência }\end{array}$ \\
\hline 1989 & 13053 & 26 & 29 & 19 & 14,56 \\
1990 & 13515 & 26 & 218 & 75 & 55,49 \\
1991 & 12595 & 24 & 119 & 6 & 4,76 \\
1992 & 12992 & 24 & 135 & 9 & 6,96 \\
1993 & 13258 & 26 & 106 & 16 & 12,07 \\
1994 & 13602 & 26 & 73 & 5 & 3,68 \\
1995 & 13955 & 26 & 103 & 0 & 0,00 \\
1996 & 14318 & 28 & 81 & 0 & 0,00 \\
1997 & 14747 & 29 & 58 & 0 & 0,00 \\
1998 & 15189 & 30 & 69 & 0 & 0,00 \\
1999 & 15472 & 31 & 176 & 0 & 0,00 \\
\hline
\end{tabular}

Tabela 4 - Número de animais a serem examinados(n), segundo Thrusfield, para se detectar pelo menos um animal positivo para raiva (d), com confiança de 95\% (1-a), a partir da população canina estimada, Município de Mogi-Guaçu, Estado de São Paulo, Brasil, de janeiro de 1989 a dezembro de 1999

\begin{tabular}{ccccc}
\hline Ano & $\begin{array}{c}\text { População canina } \\
\text { estimada }\end{array}$ & $1-\alpha$ & d & N \\
1989 & 13053 & 0,95 & 1 & 12400 \\
1990 & 13515 & 0,95 & 1 & 12839 \\
1991 & 12595 & 0,95 & 1 & 11965 \\
1992 & 12992 & 0,95 & 1 & 12342 \\
1993 & 13258 & 0,95 & 1 & 12595 \\
1994 & 13602 & 0,95 & 1 & 12922 \\
1995 & 13955 & 0,95 & 1 & 13257 \\
1996 & 14318 & 0,95 & 1 & 13602 \\
1997 & 14747 & 0,95 & 1 & 14010 \\
1998 & 15189 & 0,95 & 1 & 14430 \\
1999 & 15472 & 0,95 & 1 & 14698 \\
\hline
\end{tabular}

Guaçu, 1167 amostras de cérebros de cães. Destas, 1037 foram negativas e 130 positivas (Tabela 1).

A tabela 1 revela que, a partir do encaminhamento sistemático de materiais para exame de laboratório, os focos de raiva canina foram registrados, possibilitando determinar a distribuição destas amostras do mês de janeiro de 1989 a dezembro de 1999.

Os dados apresentados nas tabelas 1 e 2 mostram que, no ano de 1989, 29 amostras foram encaminhadas para exame 


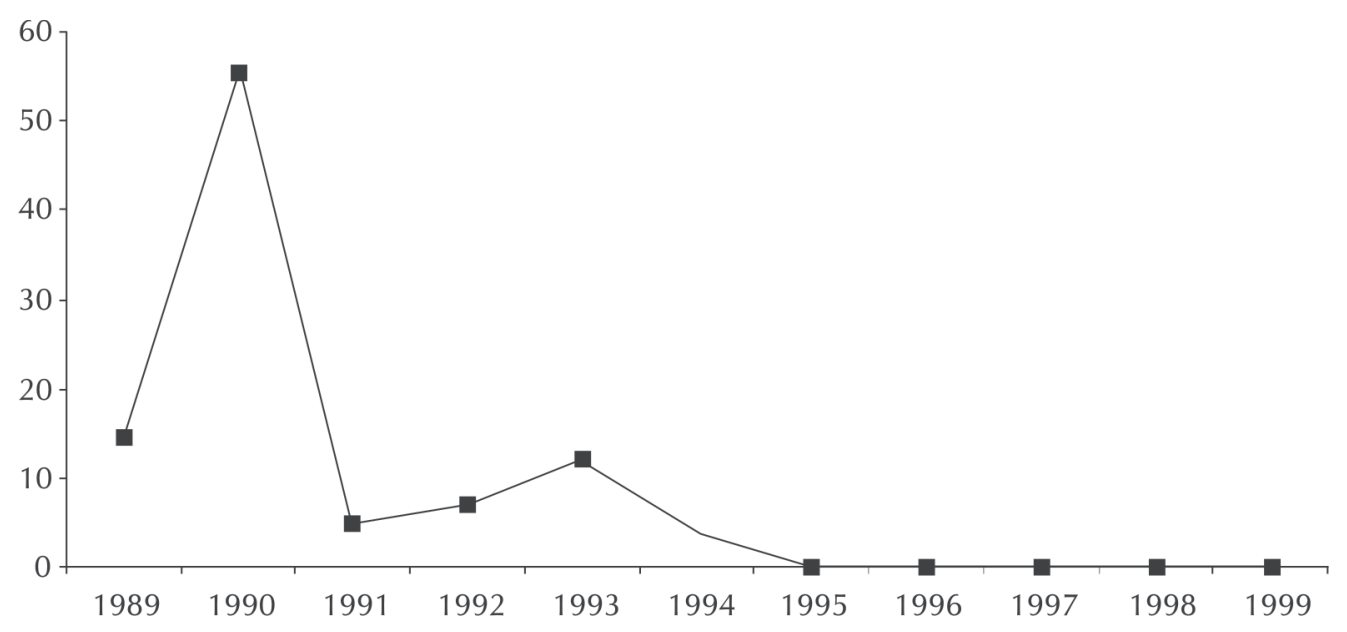

Figura 1 - Distribuição dos casos de raiva e do coeficiente de incidência (10.000 indivíduos), segundo o ano, município Mogi-Guaçu, Estado de São Paulo, Brasil, de janeiro de 1989 a dezembro 1999

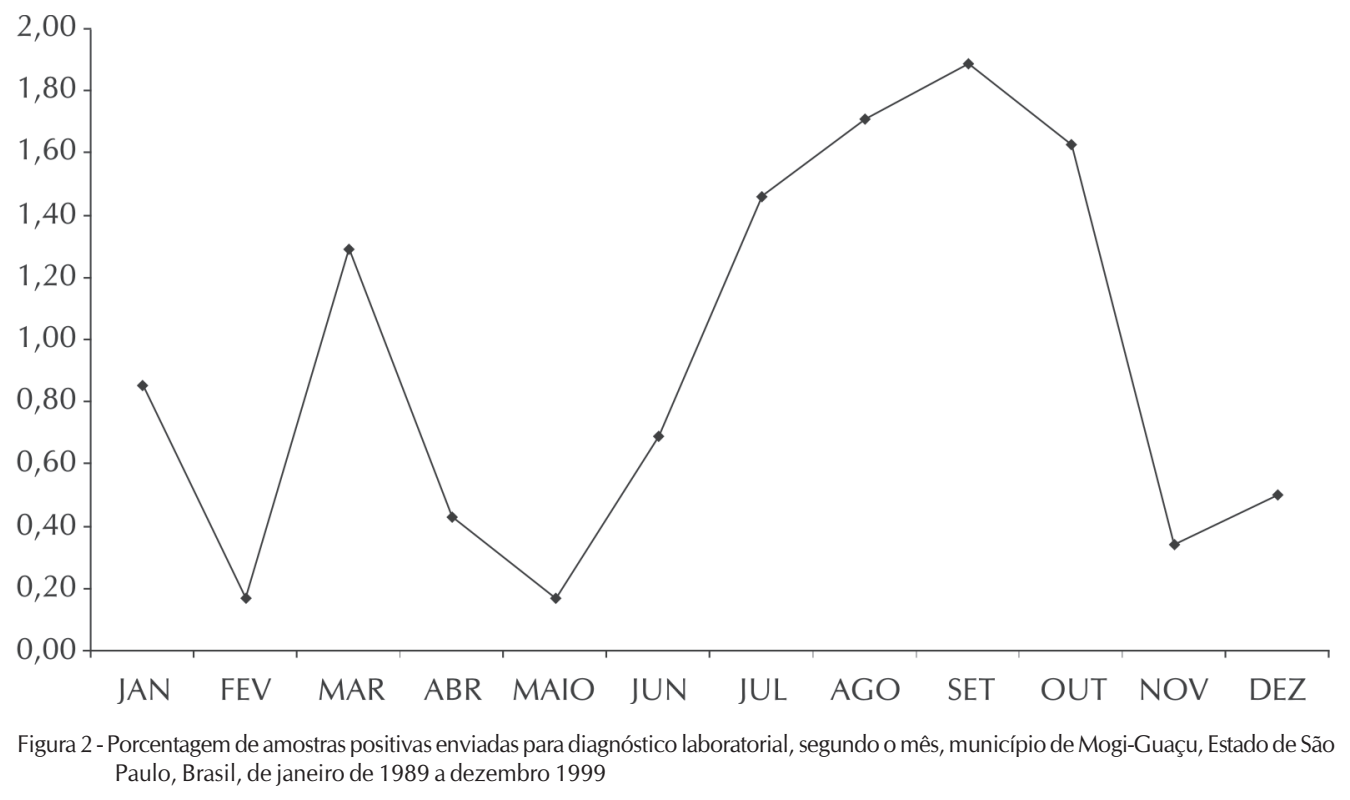

laboratorial e que deste total, 65,5\% (19/29) apresentaram resultado positivo, que período estudado. representou 1,6\% do total de 1167 amostras, no período estudado. No ano de 1990, de 218 materiais encaminhados para diagnostico laboratorial, 34,4\%.(75/218), foram positivas ou, 6,4\% (75/1167), do total de amostras enviadas para o diagnóstico, representando o maior percentual de positividade no

As tabelas 1 e 2 identificam que, no ano de 1991, de 119 amostras enviadas, 5,0\% (6/119), foram positivas, indicando uma diminuição da incidência da doença, naquele ano. Os focos ocorreram nos meses de março (2/14), abril (1/13), junho(1/11) e julho(2/8) e representaram 0,5\% (6/1167) do total das amostras do período estudado. 
No ano de 1992, ocorreu uma situação semelhante à de 1991. Os focos surgiram nos meses de abril (1/8), junho(1/9), agosto $(4 / 22)$ representando $6,9 \%(9 / 135)$ no ano ou, $0,8 \%$ (9/1167) no período de janeiro de 1989 a dezembro de 1999.

Pode-se observar na tabela 2 , um incremento da porcentagem de casos positivos em 1993, embora não tenha resultados positivos nos meses de fevereiro, março, abril, maio e junho, obteve-se $15 \%$ (16/106) de positividade no ano, o que representou $1,4 \%$ (16/1167), sendo, o segundo maior percentual de positividade do período estudado.

As tabelas 1 e 2 , mostram que, no ano de 1994, nos meses de janeiro (3/9), abril (1/3) e maio (1/5), foram diagnosticados os últimos casos de raiva canina no Município de Mogi Guaçu. Do total de amostras enviadas, 3,8\% (5/73) foram positivas, o que representou um percentual de $0.43 \% \quad(5 / 1167)$ de positividade no período estudado.

$\mathrm{Na}$ tabela 3 pode-se observar o coeficiente de incidência pôr 10.000 indivíduos, no período compreendido entre 1989 e 1999.

A tabela 4 mostra o que seria teoricamente, o tamanho da amostra para detectar pelo menos um animal doente no Município de Mogi-Guaçu, segundo Thrusfield ${ }^{9}$. Comparando-se as tabelas $1 \mathrm{e}$ 4, verifica-se que o tamanho da amostra calculada está muito próxima da população canina estimada, sendo muito diferente do número de amostras efetivamente enviada para diagnóstico pelo CCZ de Mogi-Guaçu, que seguiu a recomendação apresentada nos estudos de Shneider?.

$\mathrm{Na}$ figura 1, pode-se visualizar o declínio dos casos de raiva e os dois ciclos, cada um deles com dois anos de duração. $\mathrm{Na}$ figura 2, observa-se a sazonalidade da epizootia no período estudado.

O comportamento cíclico da doença pode ser explicado pelas condições ambientais e pelo aumento dos suscetíveis. O bloqueio vacinal e os óbitos, possibilitaram uma diminuição do número de suscetíveis resultando no decréscimo do número de casos positivos. $\mathrm{O}$ aparecimento de um novo ciclo da doença pode ser explicado pela introdução de animais não vacinados, devido a renovação da população canina, favorecendo a reintrodução do vírus da raiva. Entre janeiro de 1989 e dezembro de 1999, os meses de março, agosto, setembro e outubro, apresentaram os maiores percentuais de casos de raiva canina. $\mathrm{O}$ mês de setembro apresentou o maior percentual de positividade $(1,89 \%$ dos casos de raiva) no período estudado e o menor percentual $(0,17)$ pode ser observado nos meses de fevereiro e maio.

$\mathrm{Na}$ cidade de $\mathrm{Recife}^{8}$, foi descrita a sazonalidade da raiva canina, demonstrando uma predominância de casos nos meses de março, julho, setembro e outubro, à semelhança do que ocorreu em Mogi-Guaçu. Esses aspectos também foram observados no Chile, onde ocorreu uma tendência de redução dos casos de raiva nos primeiros dez anos após a implantação de um programa nacional de controle. A sazonalidade e os ciclos a cada cinco anos também deixam de ser observados com a consolidação do programa ${ }^{5}$. Entretanto, quando da avaliação da epizootia de raiva ocorrida na cidade de Ribeirão Preto no ano de 1995 não foi encontrada variação na distribuição de casos de raiva canina nos meses do ano?.

Da mesma forma que em outras cidades do Estado e do país, os resultados obtidos pelo município de Mogi-Guaçu foram em decorrência da criação de uma estrutura institucional que possibilitou a disponibilidade de recursos financeiros o que possibilitou a implantação, implementação e a manutenção do programa de controle da raiva no município. As ações de vigilância epidemiológica implantadas pelo Município de Mogi-Guaçu, permitiram o monitoramento das ações de controle da raiva, fazendo com que o município saísse da condição inicial de epizootia.

O quadro 1 mostra que, a partir de 
1995, com o estabelecimento de uma rotina nas ações de controle da raiva, a probabilidade de encontrar uma amostra positiva é cada vez menor necessitando, portanto, de uma amostra cada vez maior. De acordo com a análise realizada, constatou-se que o número de amostras enviadas para diagnóstico laboratorial deveria ter um tamanho próximo ao da população canina estimada.

\section{Conclusão}

O Município de Mogi-Guaçu, apresentou um importante decréscimo na incidência de casos de raiva canina, a partir do envio sistemático de amostras de cérebros de cães para diagnóstico laboratorial, por ter orientado as ações de controle durante o período epidêmico, de acordo com o Programa Nacional de Controle da Raiva.

Ocorreram dois ciclos, que puderam ser observados a partir do calculo do coeficiente de incidência, cada um deles com três anos de duração. O primeiro ciclo ocorreu entre 1989 e 1991 e o segundo ciclo, de 1992 a 1994.

Com esses resultados, pode-se dizer que a implantação, a intensificação, a manutenção, e o aprimoramento das ações de controle da raiva pelo CCZ de Mogi-
Guaçu foi de grande impacto, pois, partir do ano de 1995, impediu a circulação do vírus rábico.

Enquanto houve a circulação do vírus rábico em cães no Município de MogiGuaçu, o envio de 0,2\% de amostras de cérebro para diagnóstico laboratorial, em relação a população canina estimada, possibilitou detectar cães positivos para raiva.

No período em que os resultados laboratoriais foram negativos, compreendidos entre os anos de 1995 a 1999, o tamanho da amostra para encontrar pelo menos um animal positivo, precisaria ser probabilisticamente cada vez maior, tendendo à população total.

Faz-se necessários novos estudos sobre o número de amostras a serem enviadas para diagnóstico laboratorial para detectar a circulação do vírus rábico em áreas de raiva controlada.

\section{Agradecimentos}

Os autores agradecem a Elizabeth Amatuzzi da C. Aguiar e a Luzia Fátima Alves Martorelli, responsáveis pela rotina dos diagnósticos de raiva, do Laboratório do Centro de Controle de Zoonoses, Centro de Referência Nacional e Órgão Colaborador da Organização Mundial de Saúde para Zoonoses Urbanas.

\section{Epidemiologic surveillance of the rabies virus using the brain immunoflorescence test on a sample of a canine population. Probality and analysis with actual cases from Mogi-Guaçu, SP, Brazil, During the 1989- 1999 period}

\begin{abstract}
The validty of a systematic laboratory exam that consists in examining the nervous system of a canine population sample in a given area was anlyzed, as a proper strategy for epidemiological survilance of the rabies virus presence. The analysis was based on the databank of the County of Mogi-Guaçu, SP, Brazil, referring to the historical period between January 1989 and december 1999. During this period 1,167 animals were examined and an immunofluorescence test applied to rabies showed that 130 animals $(11.2 \%)$ were positive. The sample size for detecting at least one positive animal was calculated by using the formula $\mathrm{n}=\left\{1-(1-\alpha)^{1 / \mathrm{d}}\right\}(\mathrm{N}-\mathrm{d} / 2\}+1$. Between 1989 and 1994
\end{abstract}

Key-words:

Dog.

Survillance.

Rabies.

Mogi-Guaçu.

São Paulo (Estado). 
the size of sample was calculated based on the real number of recorded cases. Between 1995 and 1999, as there were no new cases of canine rabies, the analysis considered a hypothetical presence of a confirmed case. It was also carried out a simulation of the number of rabies cases that should occur so that the sample effectively used by the Rabies Control Service would be able to reveal the presence of at least one positive animal. Results showed that in the period from 1989 to 1994 , in when the annual frequecy of canine rabies cases varied from 5 to 75 cases, the ideal size of sample should be from 12,400 to 12,922. In the period from 1995 to 1999, when no canine rabies cases were recorded, the sample size would be from 13,257 to 14,698 if at least one case occurred. Thus, one can understand that in therms of probability, the proposed strategy is not recommended for the epidemiological survilance of rabies virus presence, since the number of animal to be examined is not feasible in real situation.

\section{Referências}

1 JACKSON, A. Rabies In: NATHANSON, N. et al. (Ed.). Viral pathogenesis. Philadelphia: LippincottRaven, 1997. p. 575-588.

2 BRASIL. Ministério da Saúde. Fundação Nacional de Saúde. Centro Nacional de Epidemiologia. Guia de vigilância epidemiológica: raiva. Brasília (DF): FUNASA, 1994. p. 275-289.

3 PROGRAMA Regional para la eliminación de la rabia humana transmitida por el perro en las Américas: Análisis de Progreso. In: REUNIÓN INTERAMERICANA DE SALUD ANIMAL A NIVEL MINISTERIAL, 11., 1999, Washington. Proceeding... Washington: Organização Panamericana de Saúde, 1999.

4 BÖGEL K.; MESLAN, F-X. Economics of human and canine rabies elimination: guideline for program orientation. Bolletin of the World Health Organization, v. 68, n. 3, p. 281-291, 1990.

5 SÃO PAULO (Estado). Secretaria de Estado da Saúde. Instituto Pasteur. Manual técnico sobre orientação para projetos de centros de controle de zoonoses. São Paulo: Instituto Pasteur, 1998. n. 2.

6 CÔRTES, J. A. Epidemiologia: conceitos e princípios fundamentais. São Paulo: Varela, 1993. 227 p.

7 SCHNEIDER, M. C. Estudo de avaliação sobre área de risco para raiva no Brasil. 1990. 230 f. (Mestrado em Epidemiologia) - Escola Nacional de Saúde Pública, FIOCRUZ, Rio de Janeiro, 1990.

8 BRASIL. Ministério da Saúde. Fundação Nacional de Saúde. Sistema Nacional de Agravos de Notificação. Tabela. Disponível em: <http://www.saude.gov.br>. Acesso em: jul. 2001.
9 THRUSFIELD, M. Surveys. In: Veterinary epidemiology. 2nd. ed. Cambridge: Blackwell Science, 1995. cap. 13, p. 178-195.

10 GOLDWASSER, R. A.; KISSILING, R. E. Fluorescent antibody staining of street and fixed rabies virus antigens. Proceeding of a Society for Experimental Biology and Medicine, v. 98, p. 219-223, 1958.

11 KAPLAN, M. M.; KOPROWISK, H. Ed. Laboratory techniques in rabies. 3. ed. Geneva: WHO, 1973. 476 p.

12 LIMA JR., A. D. Dinâmica populacional canina e a persistência da raiva na cidade de recife (PE), nordeste do Brasil, 1987-1997. 1999. 187 f. Tese (Doutorado em Epidemiologia) - Faculdade de Saúde Pública, Universidade de São Paulo, São Paulo, 1999.

13 ERNST, S. N.; FABREGA, F. A time series analysis of rabies control programme in Chile. Epidemiology and Infection, v. 3, n. 103, p. 651-657, 1989.

14 PASSOS, A. D. C. et al. Epizootia de raiva na área urbana da Ribeirão Preto, SP, Brasil. Caderno de Saúde Pública, Rio de Janeiro, v. 14, n. 4, p. 735-740, 1998. 